\title{
Irradiation of the Juvenile Brain Provokes a Shift from Long-Term Potentiation to Long-Term Depression
}

\author{
Giulia Zanni $^{\mathrm{a}, \mathrm{c}}$ Kai Zhou ${ }^{\mathrm{a}}$ Ilse Riebe ${ }^{\mathrm{b}}$ Cuicui Xie $^{\mathrm{a}}$ Changlian Zhu $^{\mathrm{a}}$ \\ Eric Hanse $^{\mathrm{b}}$ Klas Blomgren ${ }^{\mathrm{c}}$ \\ ${ }^{a}$ Center for Brain Repair and Rehabilitation and bepartment of Neuroscience and Physiology, University \\ of Gothenburg, Gothenburg, and 'Karolinska Institute, Department of Women's and Children's Health, \\ Karolinska University Hospital, Stockholm, Sweden
}

\section{Key Words}

Neurogenesis · Rat · Juvenile brain · Neurooncology ·

Radiation therapy

\begin{abstract}
Radiotherapy is common in the treatment of brain tumors in children but often causes deleterious, late-appearing sequelae, including cognitive decline. This is thought to be caused, at least partly, by the suppression of hippocampal neurogenesis. However, the changes in neuronal network properties in the dentate gyrus (DG) following the irradiation of the young, growing brain are still poorly understood. We characterized the long-lasting effects of irradiation on the electrophysiological properties of the DG after a single dose of 6-Gy whole-brain irradiation on postnatal day 11 in male Wistar rats. The assessment of the basal excitatory transmission in the medial perforant pathway (MPP) by an examination of the field excitatory postsynaptic potential/volley ratio showed an increase of the synaptic efficacy per axon in irradiated animals compared to sham controls. The paired-pulse ratio at the MPP granule cell synapses was not affected by irradiation, suggesting that the release probability of neurotransmitters was not altered. Surprisingly, the induction of
\end{abstract}

long-term synaptic plasticity in the DG by applying 4 trains of high-frequency stimulation provoked a shift from longterm potentiation (LTP) to long-term depression (LTD) in irradiated animals compared to sham controls. The morphological changes consisted in a virtually complete ablation of neurogenesis following irradiation, as judged by doublecortin immunostaining, while the inhibitory network of parvalbumin interneurons was intact. These data suggest that the irradiation of the juvenile brain caused permanent changes in synaptic plasticity that would seem consistent with an impairment of declarative learning. Unlike in our previous study in mice, lithium treatment did unfortunately not ameliorate any of the studied parameters. For the first time, we show that the effects of cranial irradiation on long-term synaptic plasticity is different in the juvenile compared with the adult brain, such that while irradiation of the adult brain will only cause a reduction in LTP, irradiation of the juvenile brain goes further and causes LTD. Although the mechanisms underlying the synaptic alterations need to be elucidated, these findings provide a better understanding of the effects of irradiation in the developing brain and the cognitive deficits observed in young patients who have been subjected to cranial radiotherapy.

(c) 2015 S. Karger AG, Basel

\begin{tabular}{ll}
\hline KARGER 125/5 & $\begin{array}{l}\text { ○ 2015 S. Karger AG, Basel } \\
0378-5866 / 15 / 0373-0263 \$ 39.50 / 0 \quad \text { Karger } \\
\text { Epen access }\end{array}$ \\
E-Mail karger@karger.com & $\begin{array}{l}\text { Thisis an Open Access article licensed under the terms of the } \\
\text { Creative Commons Attribution-NonCommercial 3.0 Un- } \\
\text { ported license (CC BY-NC) (www.karger.com/OA-license), } \\
\text { applicable to the online version of the article only. Distribu- } \\
\text { tion permitted for non-commercial purposes only. }\end{array}$
\end{tabular}

Klas Blomgren

Department of Women's and Children's Health

Karolinska University Hospital Q2:07

SE-17176 Stockholm (Sweden)

E-Mail Klas.blomgren@ki.se 


\section{Introduction}

Radiotherapy is part of the first-line treatment for the eradication of primary and metastatic CNS tumors, but the impact on the quality of life following such treatment represents a stumbling block in the progression of the field [1]. The young developing brain represents a special concern as it was empirically found to be more sensitive to irradiation than the adult brain [2-5]. Irradiation induces long-lasting changes in the neuronal architecture, resulting in growth retardation and detrimental neurocognitive consequences such as learning deficits, particularly in children $[6,7]$. This degeneration appears to be due, at least partly, to irradiation targeting highly proliferative regions of the brain harboring neural stem cells, the subgranular zone of the hippocampus and the subventricular zone. The irradiation-induced impairment of hippocampal neurogenesis correlates with cognitive dysfunctions in rats and mice $[8,9]$. Neurogenic areas are particularly susceptible to ionizing radiation, and this is especially true for the hippocampus [10], a structure of the brain involved in the formation of explicit memories [11]. Although most studies have found reduced cognitive performance after irradiation, there are also conflicting reports, including one where 4-Gy whole-body X-ray irradiation of young mice resulted in an impaired extinction of memories acquired 2 weeks earlier [12] and another one where $0.25-\mathrm{Gy}$ whole-body ${ }^{28} \mathrm{Si}$ irradiation enhanced long-term potentiation (LTP) and contextual fear conditioning [13]. The first of these studies is compatible with the recent study by Akers et al. [14], demonstrating that hippocampal neurogenesis positively regulates forgetting. The cellular mechanisms underlying memory formation reside, at least partly, in the long-term modulation of the synaptic efficacy, operated by 2 opposing phenomena: LTP [15] and long-term depression (LTD) [16]. The basic mechanisms of induction require the activation of $\mathrm{N}$-methyl-D-asparate receptors(NMDARs) and $\mathrm{Ca}^{2+}$ influx in the postsynaptic terminals, and the interplay between the inhibitory and excitatory signaling is important for this plasticity to occur [17-19]. While LTP is crucial for information storage and synaptic strengthening, LTD is believed to shape previously stored information allowing enhancement of the signal-to-noise ratio in the information processing [16]. The dentate gyrus (DG) represents the first relaying station for the processing of information in the hippocampus, and neurogenesis plays an important role in pattern separation, a mechanism necessary to disambiguate distinct inputs and facilitate memory formation [20-22]. Using irradia- tion, as well as more selective forms of neural stem cell ablation, it has been shown that LTP in medial perforant pathway (MPP) synapses onto adult-born granule cells of the rat DG accounts for about $10 \%$ of the total DG LTP $[23,24]$. Since newborn, in contrast to mature, granule cells exhibit depolarizing GABAA-mediated responses, this LTP in synapses onto adult-born granule cells can be isolated using high-frequency stimulation (HFS) in the presence of intact GABAA-mediated signaling [24, 25]. Impairment of this process is likely correlated with the cognitive decline observed in young patients who undergo radiotherapy.

Lithium has been considered a promising candidate in the prevention and recovery after various types of brain injury, including cranial irradiation, and several studies have demonstrated beneficial effects in restoring adult neurogenesis as well as synaptic plasticity in different disease models [26-29]. Lithium appears to restore cognitive function in adult as well as in young [29] mice following cranial irradiation and is thought to act partially through the inhibition of neural apoptosis [30] as well as by boosting endogenous neurogenesis [31]. At present, there is little knowledge of irradiation-induced damage to the brain during development, but since the juvenile brain is even more sensitive to ionizing irradiation than the adult brain $[2,5,32]$, it is of great importance to define the mechanisms that lead to cognitive impairment following such treatment and to conceive therapeutic approaches to rescue the young developing brain from cognitive decline. Here, we present novel findings on the late-appearing functional impairments related to neurogenesis and synaptic plasticity after irradiation of the young brain. We report how neural plasticity is altered in the juvenile rat brain after cranial irradiation, mechanisms which have not previously been described. Our findings provide a better understanding of how irradiation changes the juvenile brain, thereby enabling us to design protective strategies.

\section{Materials and Methods}

Animals and Ethical Permission

Male Wistar rats were purchased from Charles Rivers Laboratories (Sulzfeld, Germany). The animals were housed at the animal facility in Gothenburg (Laboratory of Experimental Biomedicine) and were kept on a 12-hour light cycle with food and water available ad libitum. All experiments were approved by the animal research ethics committee (Gothenburg committee of the Swedish Agricultural Agency), in accordance with the national animal welfare legislation (202-2012). 


\section{Lithium Administration}

Lithium chloride (LiCl; Aldrich, St. Louis, Mo., USA) was dissolved in saline and injected i.p. with a loading dose of $2 \mathrm{mmol} /$ $\mathrm{kg}$ followed by daily $1-\mathrm{mmol} / \mathrm{kg}$ injections, starting on postnatal day 7 and continuing for 14 consecutive days. Sham animals received an equivalent dose of saline.

\section{Irradiation Procedure}

The irradiation of the animals was performed using a linear accelerator (Varian Clinac 600CD; Radiation Oncology System LLC, San Diego, Calif., USA) with 4 MV nominal photon energy and a dose rate of $2.3 \mathrm{~Gy} / \mathrm{min}$. A single dose of $6 \mathrm{~Gy}$ was delivered to each animal on postnatal day 11 .

The dose variation within the target volume was estimated to be $\pm 5 \%$. On postnatal day 11 , the rats were anesthetized with a $50-\mathrm{mg} / \mathrm{kg}$ i.p. injection of tribromoethanol (Avertin, SigmaAldrich, Stockholm, Sweden) and placed in a prone position (head to gantry) on a Styrofoam bed. The whole brain was irradiated with a radiation field of $2 \times 2 \mathrm{~cm}$. The source-to-skin distance was approximately $99.5 \mathrm{~cm}$. In order to spread the dose evenly throughout the tissue, the head was covered with a $1-\mathrm{cm}$ tissueequivalent bolus material. The entire procedure was completed within $5 \mathrm{~min}$. After irradiation, the pups were returned to their dams until weaning. The sham-irradiated controls were anesthetized but not irradiated.

\section{Electrophysiology}

Slice Preparation and Solutions

Four months after the irradiation, the rats were anesthetized with isoflurane (Abbott) prior to decapitation. The brain was removed quickly and placed in oxygenated ice-cold artificial cerebrospinal fluid containing (in $\mathrm{mM}$ ): 219 glycerol, $2.5 \mathrm{KCl}, 1.2 \mathrm{CaCl}_{2}$, $7 \mathrm{MgCl}_{2}, 26 \mathrm{NaHCO}_{3}, 1.2 \mathrm{NaH}_{2} \mathrm{PO}_{4}$ and 11 glucose. Transverse hippocampal slices of $300 \mu \mathrm{m}$ thickness were cut with a vibratome (HM 650V Microm, Germany) in the same ice-cold solution. The slices were incubated in a chamber at $32^{\circ} \mathrm{C}$ and perfused with artificial cerebrospinal fluid containing (in $\mathrm{mM}$ ): $124 \mathrm{NaCl}, 2 \mathrm{KCl}$, $2 \mathrm{CaCl}_{2}, 4 \mathrm{MgCl}_{2}, 26 \mathrm{NaHCO}_{3}, 1.25 \mathrm{NaH}_{2} \mathrm{PO}_{4}, 0.5$ ascorbic acid, 3 myoinositol, 4 D,L-lactic acid and 10 D-glucose. The slices were allowed to equilibrate for $2 \mathrm{~h}$ before being placed in the recording chamber, perfused with a constant flow $\left(\approx 2 \mathrm{ml} \cdot \mathrm{min}^{-1}\right)$ at $30-32^{\circ} \mathrm{C}$. The perfusion fluid contained artificial cerebrospinal fluid with the following composition (in mM): $129 \mathrm{NaCl}, 20 \mathrm{NaCHO}_{3}, 1.24$ $\mathrm{NaH}_{2} \mathrm{PO}_{4}, 3 \mathrm{KCl}, 2 \mathrm{CaCl}_{2}$ and $1 \mathrm{MgCl}_{2}$. All solutions were continuously bubbled with $95 \% \mathrm{O}_{2}$ and $5 \% \mathrm{CO}_{2}$ and kept at $\mathrm{pH}$ 7.4.

Field Recordings and Analysis

A bipolar tungsten electrode was positioned in the MPP in the middle of the molecular layer. The evoked excitatory postsynaptic potential was recorded about $300 \mu \mathrm{m}$ away from the stimulation electrode at the same distance from the granule cell layer by using a glass capillary micropipette filled with $1 \mathrm{M} \mathrm{NaCl}$ (tip resistance 1-3 M $\Omega$ ). Field excitatory postsynaptic potentials (fEPSPs) were sampled at $10 \mathrm{kHz}$ and filtered at $3 \mathrm{kHz}$ with an Axon CNS Multiclamp 700B amplifier (Molecular Devices) running with the Clampex software (Molecular Devices). Input-output (I-O) curves and paired pulses were recorded $10 \mathrm{~min}$ after the electrodes were in place. For the I-O curves, we tested 5 different stimulation intensities, each consisting of 6 stimuli at $0.05 \mathrm{~Hz}$. Paired-pulse stimulation (interpulse interval $50 \mathrm{~ms}$ ) was evoked 9 times at $0.05 \mathrm{~Hz}$.
For paired pulse and for test pulses in the LTP experiments, the stimulus intensity was set such that it produced the largest possible fEPSP that did not exhibit any signs of population spike activity. During the HFS in the LTP experiments, the stimulus intensity was doubled to ensure strong induction $[33,34]$. The stimuli consisted of biphasic constant current pulses $(20-40 \mu \mathrm{A}, 200 \mu$ s; STG 1002 Multi-Channel Systems MCS Gmbh, Reutlingen, Germany) every $20 \mathrm{~s}$. After $10 \mathrm{~min}$ of stable baseline responses to the test pulse stimulation, HFS (at twice the test pulse stimulation intensity) was applied to induce LTP. The HFS consisted of 4 trains of $1 \mathrm{~s}$ each, $100 \mathrm{~Hz}$ within the train, repeated every $15 \mathrm{~s}$, as previously described [24]. After the HFS, evoked fEPSPs were recorded for $40 \mathrm{~min}$ at $0.05 \mathrm{~Hz}$. The fEPSPs were analyzed off-line using custom-made IGOR Pro (Wave Metrics, Lake Oswego, Oreg.) software. For the I-O curves, the average $(n=6)$ presynaptic volley was plotted against the average fEPSP slope for the 5 different stimulus intensities, and the slope of the linear regression between these 5 data points was taken as the I-O value for the individual experiment. The paired-pulse ratio (PPR) was calculated as the ratio of the initial slope of the 2 nd fEPSP divided by the initial slope of the 1st fEPSP. The mean slope of the fEPSPs recorded during the 10 min preceding LTP induction (baseline) was normalized to 1 . The LTP response within each group was determined as the difference between the mean of the fEPSPs slopes of the last 10 min after LTP induction and the mean of the fEPSPs slopes of the baseline.

\section{Immunohistochemistry}

A separate set of animals was used for immunohistochemistry. Four months after the irradiation, the animals were deeply anesthetized with pentobarbital, and saline solution $(0.9 \% \mathrm{NaCl})$ was delivered transcardially throughout the left ventricle followed by $4 \%$ paraformaldehyde. The brains were removed, keeping the olfactory bulb intact, and put into vials with $4 \%$ paraformaldehyde fixative over night at $+4^{\circ} \mathrm{C}$. After $24 \mathrm{~h}$, the brains were transferred into $30 \%$ sucrose in $0.1 \mathrm{M}$ phosphate buffer. The brains were cryosectioned sagittally as 1:12 consecutive series of $25 \mu \mathrm{m}$-thick sections on a sliding microtome (Leica SM 2000R). The sections were stored in a cryoprotectant solution containing $25 \%$ ethylene glycol, $25 \%$ glycerol and $0.1 \mathrm{M}$ phosphate buffer $(\mathrm{pH} 7.4)$ at $+4^{\circ} \mathrm{C}$ for further histological analysis. For chromogenic immunodetection (3,3-diaminobenzidine staining), free-floating sections were washed in Tris-buffered saline for $30 \mathrm{~min}$ (Trizma HCL, Trizma base, $\mathrm{NaCl}, \mathrm{pH} 7.5$ ) and treated with $0.6 \% \mathrm{H}_{2} \mathrm{O}_{2}$ for $30 \mathrm{~min}$ to reduce the activity of the endogenous peroxidases and hence the background. For doublecortin (DCX) detection, an antigen retrieval step was used, heating in $10 \mathrm{~mm}$ sodium citrate buffer, $\mathrm{pH} 6.0$, at $80^{\circ} \mathrm{C}$ for $20 \mathrm{~min}$. For parvalbumin (PV) detection, the sections were pretreated for antigen retrieval with $10 \mathrm{~mm}$ sodium citrate buffer, $\mathrm{pH} 8.5$, at $80^{\circ} \mathrm{C}$ for $30 \mathrm{~min}$. For all immunostainings, the sections were incubated in blocking solution $(0.1 \%$ Triton $\mathrm{X}-100,3 \%$ donkey serum in Tris-buffered saline) for $1 \mathrm{~h}$ at room temperature on a shaking plate and then processed with primary antibody for $72 \mathrm{~h}$. For the development of chromogenic immunodetection, we used avidin-biotin-peroxidase solution (Vectastain ABC Elite kit, Vector Laboratories, Burlingame, Calif., USA), 3,3-diaminobenzidine and $0.04 \% \mathrm{NiCl}_{2}$. The secondary antibodies were diluted 1:1,000 and kept for $2 \mathrm{~h}$ at room temperature on a shaking plate. The following primary antibodies were used: rabbit anti-PV (1:1,000, Abcam, ab11427) and goat anti-DCX (1:100, 


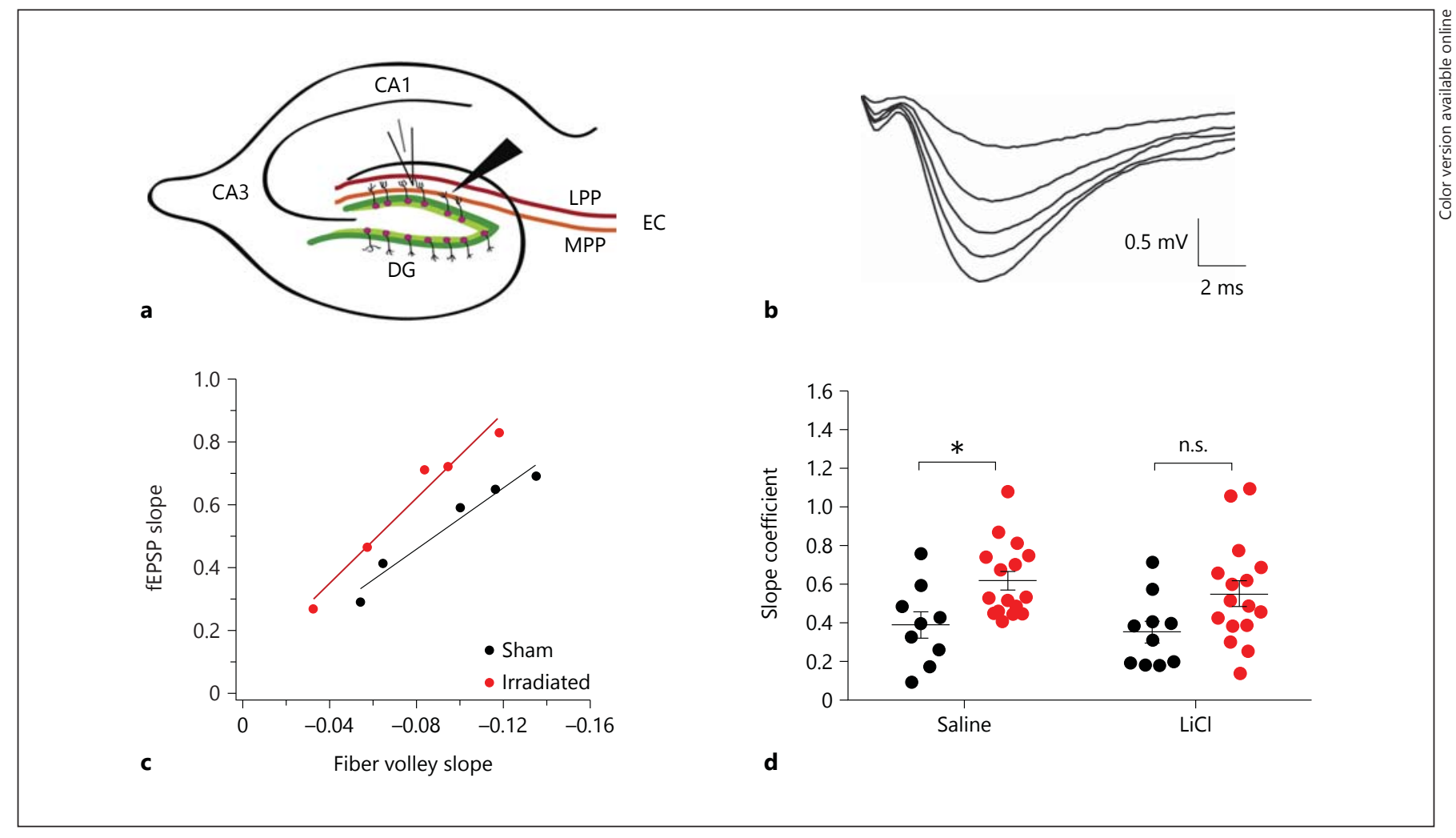

Fig. 1. Irradiation increases basal synaptic efficacy. a Schematic representation of the site of the recordings in the DG, showing the placement of the stimulation and recording electrodes. $\mathbf{b}$ Example of fEPSPs evoked using 5 different stimulation intensities. Each trace is an average of 6 recordings at the same stimulus intensity. The pulses were delivered at $0.05 \mathrm{~Hz}$. c Slopes of the linear regressions between the presynaptic volley and the fEPSPs for these 5 different stimulation intensities. d The dot plot graph shows the

Santa Cruz Biotechnology Inc., Calif., USA). The following secondary antibodies were used: biotinylated donkey anti-goat IgG $(\mathrm{H}+\mathrm{L})$ and biotinylated donkey anti-rabbit IgG $(\mathrm{H}+\mathrm{L})$ (Molecular Probes, Paisley, UK). The sections were dehydrated with NeoClear ${ }^{\circledR}$ and mounted in NeoMount ${ }^{\circledR}$ (Millipore Merck KGaA, Darmstadt, Germany). A series of every 12th section was examined to count the total number of DCX+ cells in the subgranular zone and of $\mathrm{PV}+$ cells in the hilus region across all hippocampal sections of that series. The areas of the subgranular zone and the hilus were measured. The total number of cells and contour areas were estimated using unbiased counting software (Stereo Investigator, MicroBrightField Inc., Colchester, Vt., USA).

\section{Statistical Analysis}

Statistical analysis was performed using GraphPad Prism ${ }^{\circledR}$ (La Jolla, Calif., USA). All data are expressed as means \pm standard error of the mean. The statistical differences presented here were calculated using 2-way ANOVA analysis followed by a Bonferroni post hoc test for multiple comparisons correction. $\mathrm{p}<0.05$ was considered statistically significant. slope coefficient for each group: sham $(n=9)$, irradiated $(n=16)$, sham + lithium $(n=10)$ and irradiated + lithium $(n=16)$. This coefficient was increased in irradiated animals compared to sham controls ( $\left.{ }^{*} \mathrm{p}=0.0307\right)$, but there was no significant difference between irradiated and sham animals treated with lithium. 2-way ANOVA: irradiation $\left(\mathrm{F}_{1,47}=11.3,{ }^{* *} \mathrm{p}=0.0015\right), \mathrm{LiCl}\left(\mathrm{F}_{1,47}=\right.$ $0.665, \mathrm{p}=0.4189) . \mathrm{EC}=$ Entorhinal cortex; $\mathrm{LPP}=$ lateral perforant pathway; n.s. = not significant.

\section{Results}

\section{Irradiation Enhanced Synaptic Transmission, but This Enhancement Was Not Reversed by Lithium \\ Treatment}

To evaluate the efficacy of the basal excitatory transmission in the MPP, we recorded the evoked fEPSPs in acute slices from the hippocampus of 4-month-old rats (fig. 1a). We plotted the magnitude of the fiber volley (reflecting the number of activated axons) versus the fEPSP evoked at 5 increasing stimulation intensities for each slice (fig. 1b). These data points displayed a linear relationship (fig. 1c), and we used the slope coefficient of this linear fit as a measure of the average synaptic efficacy per activated axon. The irradiated animals showed an increased synaptic efficacy per axon $(0.619 \pm 0.048)$ compared to the sham controls $(0.390 \pm 0.069)$. Two weeks of 
$1 \mathrm{mmol} / \mathrm{kg} \mathrm{LiCl}$ injected i.p. showed the same tendency in the sham controls $(0.355 \pm 0.057)$ as well as in the irradiated animals $(0.552 \pm 0.066)$; however, no statistical significance was detected in this comparison (fig. 1d).

\section{Neither Irradiation Nor Lithium Treatment Affected}

Paired-Pulse Plasticity

To examine the short-term synaptic plasticity at the MPP granule cell synapses, we performed paired-pulse recordings. A change in the PPR is indicative of a change in the release probability such that an increase in the release probability is often associated with a decrease of the PPR $[35,36]$. We used an interval of $50 \mathrm{~ms}$ between the 2 consecutively applied presynaptic stimuli (fig. 2a) and evaluated the PPR as the ratio of the slope of the 2 nd fEPSP divided by the slope of the 1st fEPSP. We observed a tendency towards irradiation having a lower PPR compared to sham; however, we did not find any significant difference in the PPR when the 4 groups were analyzed. The mean PPR of the irradiated group was $0.873 \pm 0.024$, of the sham group $0.963 \pm 0.029$, of the sham + lithium group $0.953 \pm 0.030$ and of the irradiated + lithium group $0.952 \pm 0.027$; thus, we could not find any evidence for neonatal irradiation causing any change in the glutamatergic release (fig. $2 b$ ).

\section{Irradiation Caused a Shift in the Response to HFS from LTP to LTD}

To examine the effect of early age irradiation on LTP in adulthood, we applied a protocol of 4 trains of HFS (HFS, $100 \mathrm{~Hz}$ for $1 \mathrm{~s}, 15 \mathrm{~s}$ between trains). This HFS of the MPP induced LTP in sham animals (112 $\pm 5.7 \%)$ and LTD in irradiated animals $(87.5 \pm 4.7 \%)$ (fig. 3a-c). The lithium treatment did not prevent this shift from LTP to LTD. The sham group treated with lithium exhibited no significant change in synaptic transmission (104 $\pm 6.7 \%)$, and the irradiated group treated with lithium exhibited LTD $(89.7 \pm 4.7 \%)$ (fig. $3 \mathrm{~d})$. The presynaptic volley was also measured in all groups to ascertain that the same number of axons was activated throughout the experiment (fig. 3e).

\section{Irradiation-Induced Decrease in Neurogenesis Was \\ Not Restored by Lithium Treatment}

Rapidly proliferating neuronal progenitors are a sensitive target of irradiation, and especially their integration in the DG is progressively impaired following this treatment $[5,37,38]$. According to recent findings, lithium positively regulates the neurogenic process and facilitates the reintegration of newly generated neurons after ablation of neurogenesis [26-29]. Hence, to investigate the

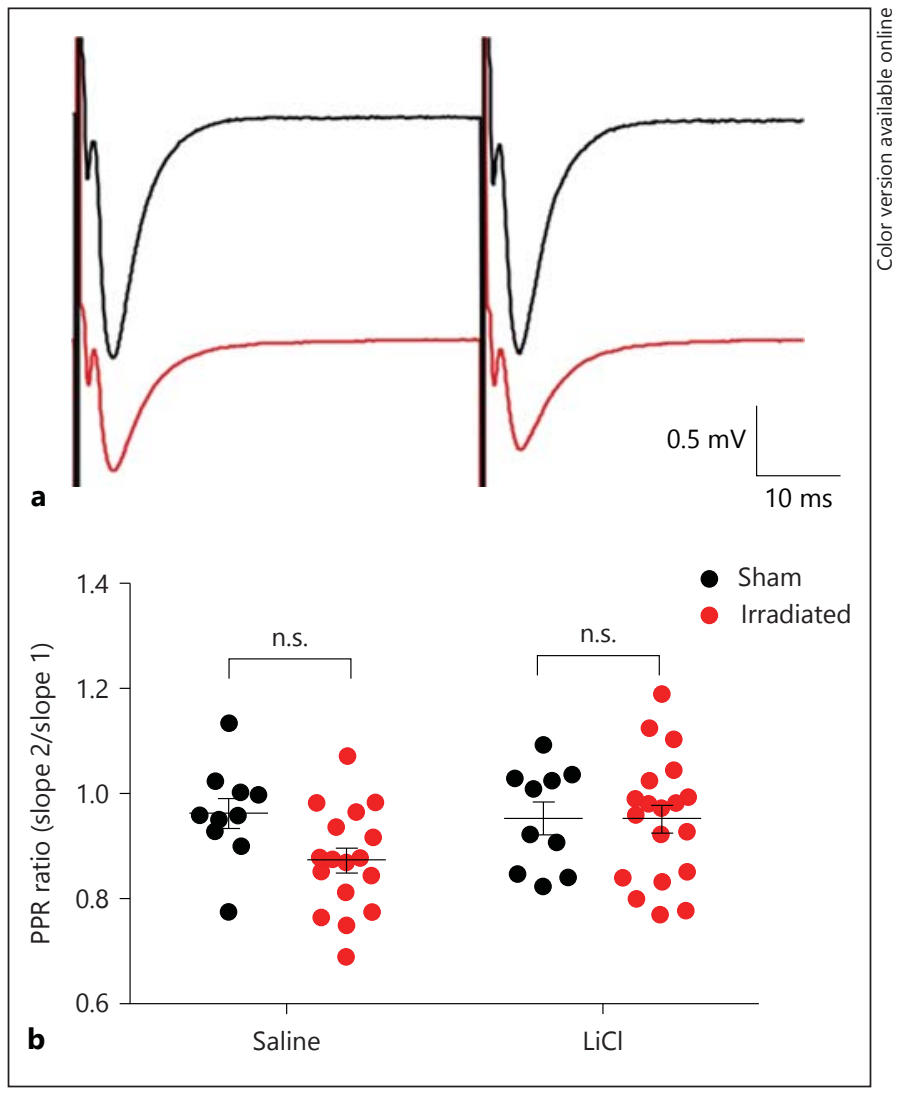

Fig. 2. Neither irradiation nor lithium treatment altered the pairedpulse plasticity at the MPP granule cell synapses. a Representative illustration of 2 individual paired-pulse recordings in the irradiation compared to the sham group in response to 2 consecutive presynaptic stimuli. b Dot plot graph showing the quantification of the PPR for each group: sham $(n=10)$, irradiated $(n=17)$, sham + lithium $(\mathrm{n}=10)$ and irradiated + lithium $(\mathrm{n}=19) .2$-way ANOVA: irradiation $\left(\mathrm{F}_{1,52}=2.44, \mathrm{p}=0.1245\right), \mathrm{LiCl}\left(\mathrm{F}_{1,52}=1.42\right.$, $\mathrm{p}=0.2383)$. n.s. $=$ Not significant.

level of integration of young adult-born neurons in the DG following juvenile irradiation and their potential recovery upon lithium treatment, we analyzed the DCXexpressing population 4 months after the insult and the therapeutic treatments (fig. $4 \mathrm{a}-\mathrm{d}$ ). As expected, we found that irradiation drastically reduced this population of immature neurons; however, lithium treatment prior to the insult and protracted for 2 weeks was not sufficient to prevent or rescue this loss (fig. 4e).

\section{Interneurons Were Not Affected by Irradiation or Lithium Treatment}

It was recently found that the activity of PV interneurons in the DG plays an important role in the fate progression of newly generated neurons as well as in the maintenance of 


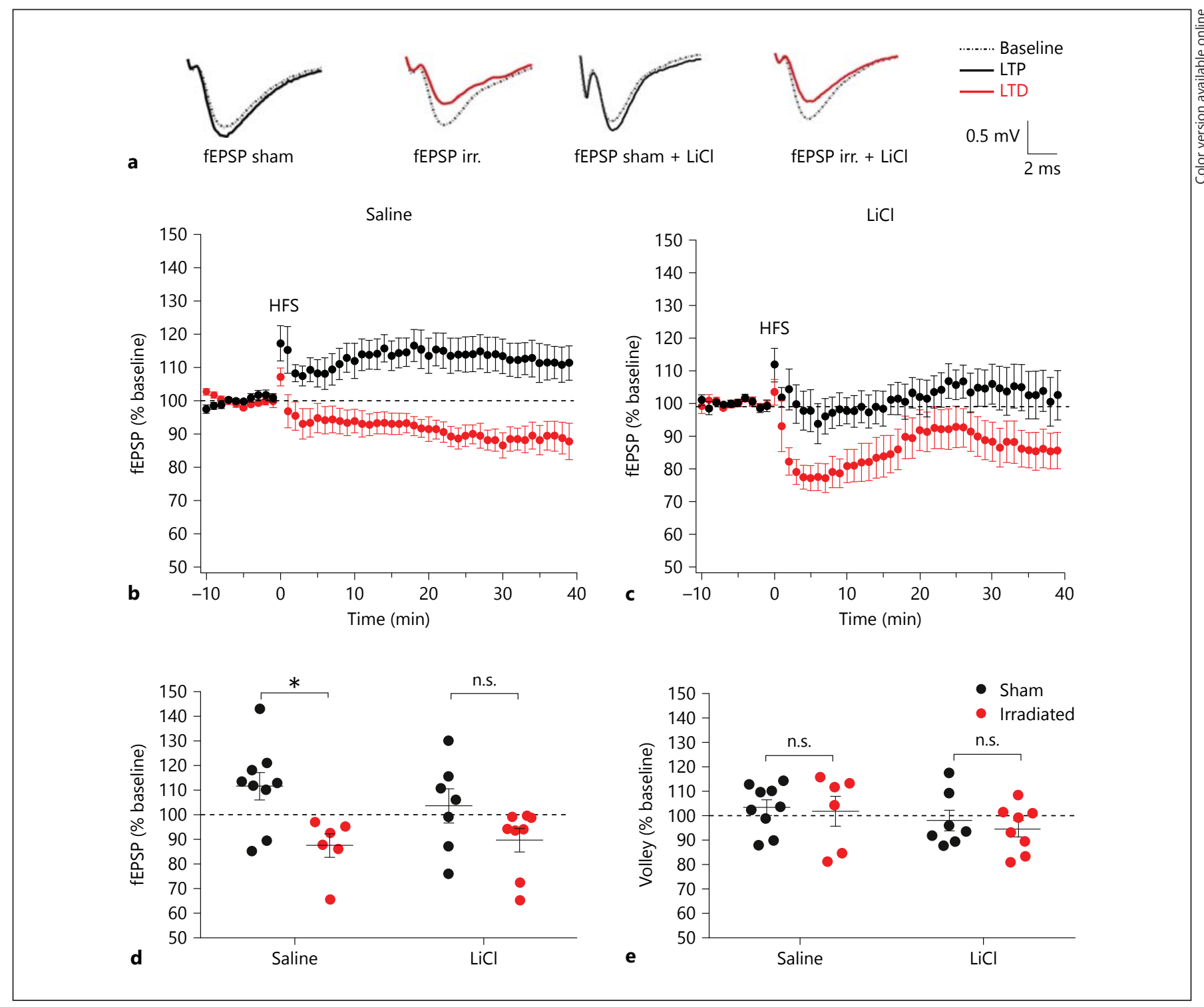

Fig. 3. Irradiation causes a switch from LTP to LTD, which is not rescued by lithium. a Representative fEPSPs before (baseline) and 30-40 min after the HFS for LTP and for LTD for each group. b, c Average fEPSP slopes normalized to the baseline in the sham $(n=9)$, irradiated $(n=6)$, sham + lithium $(n=7)$ and irradiated + lithium $(n=8)$ groups. d Quantification of the effect of HFS for each group. The difference between the irradiated and the sham

animals in the saline group was significant $\left({ }^{*} \mathrm{p}=0.0118\right)$, but there was no significant difference between irradiated and sham animals treated with lithium. 2-way ANOVA: irradiation $\left(\mathrm{F}_{1,26}=11.3\right.$, ** $\mathrm{p}=0.0024), \mathrm{LiCl}\left(\mathrm{F}_{1,26}=0.276, \mathrm{p}=0.6039\right)$. e Quantification of the volley changes for each group. 2-way ANOVA: irradiation $\left(\mathrm{F}_{1,26}=0.331, \mathrm{p}=0.5699\right), \mathrm{LiCl}\left(\mathrm{F}_{1,26}=2.32, \mathrm{p}=0.1395\right)$. irr. $=$ Irradiated; n.s. $=$ not significant.

stem cell properties [39]. Considering the overt effect of irradiation on granule cells, we hypothesized a possible repercussion on the development of hilar interneurons, which represent the main postsynaptic target of the former [40]. To glean insight on whether irradiation and subsequent lithium treatment changed the balance of these crucial inhibitory circuit elements, we analyzed the density of PV+

immunoreactivity in the hilar region of the DG (fig. 5a), and we found that neither irradiation nor lithium altered the pattern of expression of this cell type (fig. 5b). The quantification of the absolute number of PV+ cells was adjusted to the volume of the hilus (data not shown) given that irradiation causes brain growth retardation, hence a reduction of this structure is to be expected (fig. 5c). 
Fig. 4. Two weeks of lithium treatment were not sufficient to restore the DCX population. DCX immunoreactivity in the DG of the sham $(\mathrm{n}=14)(\mathbf{a})$, irradiated $(\mathrm{n}=18)$ (b), sham + lithium $(\mathrm{n}=16)(\mathbf{c})$ and irradiated + lithium $(\mathrm{n}=18)(\mathbf{d})$ groups. e Dot plot graph showing the quantification of the total number of DCX+ cells in the DG 4 months after irradiation. DCX was significantly decreased in both the saline (**** $\mathrm{p}<0.0001)$ and the lithium $(* * * * \mathrm{p}<0.0001)$ groups. 2-way ANOVA: irradiation $\left(\mathrm{F}_{1,61}=349, * * * * \mathrm{p}<0.0001\right)$, $\mathrm{LiCl}\left(\mathrm{F}_{1,61}=0.699, \mathrm{p}=0.4065\right)$. irr. = Irradiated.
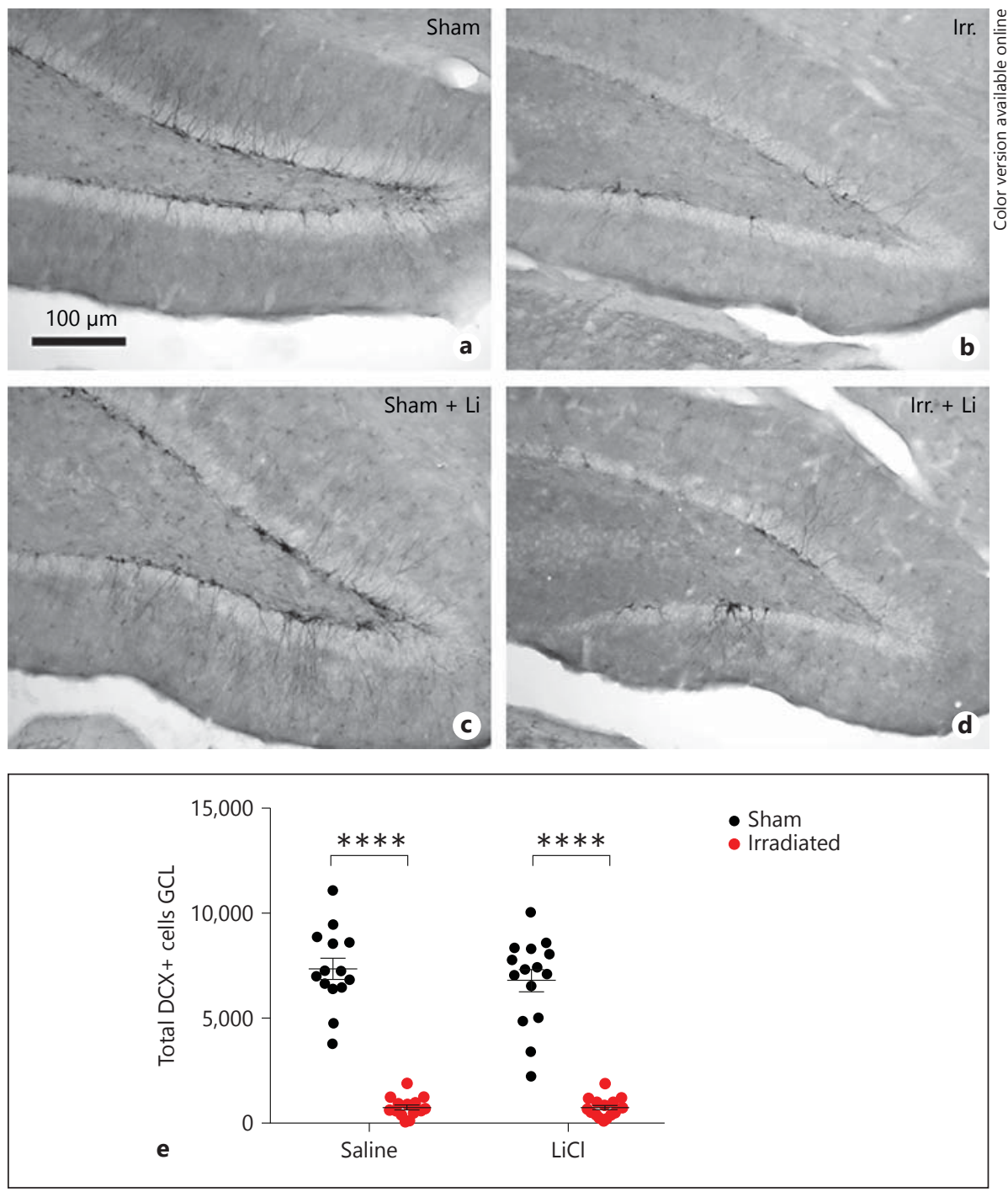

\section{Discussion}

Here, we show for the first time that irradiation of the brains of juvenile rats caused a long-lasting enhancement of the basal synaptic transmission at the MPP granule cell synapses, assessed as the relationship between the fEPSP and the fiber volley (fig. 1d). We propose that this increased synaptic strength is attributable to the depletion of adult-born granule cells (fig. 4e), which generally exhibit weaker and even silent glutamatergic synapses as compared to mature granule cells [41, 42]. Our result is generally in line with previous findings showing that irradiated adult mice displayed a stronger activation of the DG in response to perforant path activation as compared to control mice [43]. However, Ikrar et al. [43] attributed this finding mainly to a reduced synaptic inhibition via alterations in local inhibitory circuits in the DG rather than to an increased synaptic excitation of the granule cells. In our study, we quantified the number of PV+ interneurons in the hilus, but we did not find any evidence indicating a reduced number of these cells (fig. 5b). Since we did not check other types of GABAergic interneurons, and since we did not specifically examine inhibitory synaptic transmission, we cannot exclude that the long-term effects of irradiation in the DG involve alterations in inhibition. Instead, we show that irradiation results in an increased synaptic excitation of the granule cells.

Previous findings in adult neurogenesis identify young granule neurons as responsible for a unique form of longterm plasticity that can be elicited in the presence of 

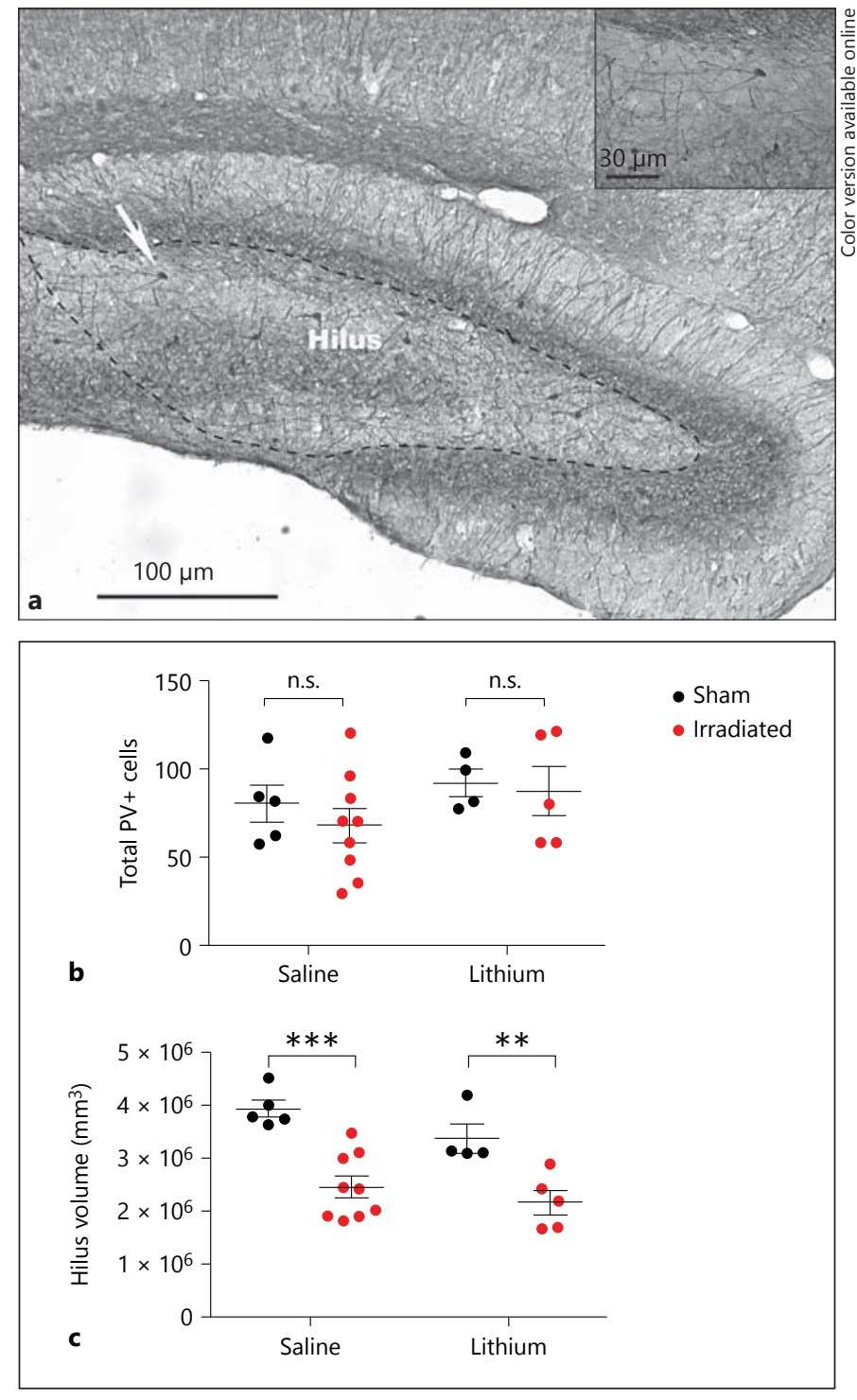

Fig. 5. The number of PV+ cells in the hilus is not affected by irradiation or by lithium. a Representative image of the PV staining in the hilus. $\mathbf{b}$ Quantification of the total number of PV+ cells for each group showing no effect of irradiation or lithium treatment on this cell type in the sham $(n=5)$, irradiated $(n=9)$, sham + lithium $(n=4)$ and irradiated + lithium $(\mathrm{n}=5)$ groups. 2 -way ANOVA: irradiation $\left(\mathrm{F}_{1,19}=0.518, \mathrm{p}=0.4806\right), \operatorname{LiCl}\left(\mathrm{F}_{1,19}=1.74, \mathrm{p}=0.2032\right)$. n.s. $=$ Not significant. c Quantification of the volume of the hilus showing the effect of the irradiation but not of the lithium treatment. Saline group ${ }^{* * *} \mathrm{p}=0.0002$, lithium group ${ }^{* *} \mathrm{p}=0.0062$. 2-way ANOVA: irradiation $\left(\mathrm{F}_{1,19}=0.334,{ }^{* * * *} \mathrm{p}<0.0001\right), \mathrm{LiCl}\left(\mathrm{F}_{1,19}=3.22, \mathrm{p}=0.0888\right)$.

GABAergic inhibition and is ablated by irradiation [23, $24,44,45]$. In the present study, we also found that the irradiation of the young and still developing brain resulted in ablation of LTP when tested in slices from adult mice. Surprisingly, however, LTP was not only ablated, but the response to the 4 trains of the $100-\mathrm{Hz}$ stimulation protocol was a clear LTD (fig. $3 \mathrm{~d}$ ), whereas in the sham group a small but consistent LTP was elicited as previously described $[24,26]$. It is well known that it is very difficult to induce LTP in adult granule cells using HFS in the slice preparation if GABAergic inhibition is not reduced $[24,33,45]$. In contrast to newborn granule cells, mature granule cells are under very strong inhibitory control, which likely explains the difficulty to induce LTP in general, and in particular, when the DG is depleted of newborn granule cells $[24,45]$. To our knowledge, however, it has not previously been shown that HFS elicits LTD in the DG.

In CA1 pyramidal neurons it has been shown that HFS results in LTD, instead of LTP, when NMDAR channels are blocked by an open channel blocker [46]. This shift to LTD does not occur when the NMDAR is blocked by an antagonist blocking the glutamate binding site, suggesting that the induction of NMDAR-dependent LTD relies on metabotropic NMDAR function, rather than on ionotropic NMDAR function with calcium influx through the channel $[46,47]$. Provided that metobotropic NMDA-dependent LTD exists in mature dentate granule cells, it is thus a likely scenario that this LTD is unmasked when the inhibitory control of the ionotropic NMDAR function is strong, and newborn granule cells are depleted.

Adult-born granule cells exhibit sparse input activity, high excitability, reduced inhibitory tone and a lower threshold for LTP, features that have proved to be important for the integration in a preexisting network and in particular for the processing of information during discriminatory tasks such as pattern separation [45, 48, 49]. Conversely, impairment of neurogenesis increases generalization and negatively affects declarative memory, thereby proving a link to cognitive functions $[23,50,51]$. Therefore, the absence of newborn neural cells and the impaired synaptic transmission observed here are likely to correlate with the cognitive decline observed in both rodents and humans after irradiation of the young brain.

In this study, we also sought to rescue these synaptic and morphological changes by administering $\mathrm{LiCl}$ for 2 consecutive weeks. It is described that lithium, a potent mood stabilizer, administered chronically to adult mice for 4 weeks, had beneficial effects in replenishing adultborn granule cells after irradiation-induced loss of neurogenesis and in rescuing LTP in a Down syndrome mode $[26,29]$.

However, despite encouraging results in a mouse model [31], in the current study we did not observe any clear effects of the treatment on any of the parameters 
described. One possible explanation is that we limited the treatment to 2 weeks. In addition, we evaluated the effects at a late time point when the lithium effect was already long since washed out, possibly resulting in a lack of measurable effects. Evaluation at an earlier time point, or chronic treatment, would be needed to be able to rule out these possibilities.

\section{Conclusions}

We provide here for the first time evidence that irradiation of the juvenile brain results in long-term alterations in the response to HFS, provoking a shift from LTP to LTD. This altered responsiveness likely contributes to the cognitive impairment known to follow cranial irradiation in juvenile rodents as well as in children. Further studies are needed to better characterize these changes in synaptic plasticity and correlate them with changes in be- havior and morphology, providing the basis for the design of a targeted intervention aiming at improving the quality of life of children who survive their cancer.

\section{Acknowledgments}

This work was supported by the Swedish Childhood Cancer Foundation (Barncancerfonden), the Swedish Research Council, the Swedish Cancer Foundation (Cancerfonden), governmental grants from the Agreement concerning Research and Education of Doctors (ALF), the Sahlgrenska Academy at the University of Gothenburg, the Frimurare Barnhus Foundation, the Wilhelm and Martina Lundgren Foundation, the Brain Foundation (Hjärnfonden) and the Swedish Radiation Safety Authority. The funding agencies had no influence on the study design.

\section{Disclosure Statement}

The authors declare to have no conflicts of interest.

\section{References}

1 Blomstrand M, Brodin NP, Munck Af Rosenschold P, Vogelius IR, Sanchez Merino G, Kiil-Berthlesen A, et al: Estimated clinical benefit of protecting neurogenesis in the developing brain during radiation therapy for pediatric medulloblastoma. Neuro Oncol 2012;14:882-889.

-2 Blomstrand M, Kalm M, Grander R, BjorkEriksson T, Blomgren K: Different reactions to irradiation in the juvenile and adult hippocampus. Int J Radiat Biol 2014;90:807-815.

-3 Duffner PK: Risk factors for cognitive decline in children treated for brain tumors. Eur J Paediatr Neurol 2010;14:106-115.

-4 Mulhern RK, Merchant TE, Gajjar A, Reddick WE, Kun LE: Late neurocognitive sequelae in survivors of brain tumours in childhood. Lancet Oncol 2004;5:399-408.

5 Fukuda A, Fukuda H, Swanpalmer J, Hertzman S, Lannering B, Marky I, et al: Age-dependent sensitivity of the developing brain to irradiation is correlated with the number and vulnerability of progenitor cells. J Neurochem 2005;92:569-584.

6 Meyers CA: Neurocognitive dysfunction in cancer patients. Oncology (Williston Park) 2000;14:75-79.

7 Kunkler PE, Anderson WJ: Noradrenergic innervation of ectopic granule cells following low-level X-irradiation. Dev Neurosci 1994; 16:74-80.

8 Monje ML, Mizumatsu S, Fike JR, Palmer TD: Irradiation induces neural precursor-cell dysfunction. Nat Med 2002;8:955-962.

-9 Rola R, Raber J, Rizk A, Otsuka S, VandenBerg SR, Morhardt DR, et al: Radiation-in- duced impairment of hippocampal neurogenesis is associated with cognitive deficits in young mice. Exp Neurol 2004;188:316-330.

10 Hellstrom NA, Bjork-Eriksson T, Blomgren K, Kuhn HG: Differential recovery of neural stem cells in the subventricular zone and dentate gyrus after ionizing radiation. Stem Cells 2009;27:634-641

11 Squire LR, Zola-Morgan S: The medial temporal lobe memory system. Science 1991;253: 1380-1386.

12 Olsen RH, Marzulla T, Raber J: Impairment in extinction of contextual and cued fear following post-training whole-body irradiation. Front Behav Neurosci 2014;8:231.

13 Raber J, Rudobeck E, Campbell-Beachler M, Allen AR, Allen B, Rosi S, et al: ${ }^{28}$ Silicon radiation-induced enhancement of synaptic plasticity in the hippocampus of naive and cognitively tested mice. Radiat Res 2014;181:362368.

14 Akers KG, Martinez-Canabal A, Restivo L, Yiu AP, De Cristofaro A, Hsiang HL, et al: Hippocampal neurogenesis regulates forgetting during adulthood and infancy. Science 2014;344:598-602.

15 Bliss TV, Collingridge GL: A synaptic model of memory: long-term potentiation in the hippocampus. Nature 1993;361:31-39.

16 Massey PV, Bashir ZI: Long-term depression: multiple forms and implications for brain function. Trends Neurosci 2007;30:176-184.

17 Mulkey RM, Malenka RC: Mechanisms underlying induction of homosynaptic longterm depression in area CA1 of the hippocampus. Neuron 1992;9:967-975.
18 Fagiolini M, Hensch TK: Inhibitory threshold for critical-period activation in primary visual cortex. Nature 2000;404:183-186.

19 Artola A, Singer W: Long-term depression of excitatory synaptic transmission and its relationship to long-term potentiation. Trends Neurosci 1993;16:480-487.

20 Van Praag H, Schinder AF, Christie BR, Toni $\mathrm{N}$, Palmer TD, Gage FH: Functional neurogenesis in the adult hippocampus. Nature 2002;415:1030-1034.

21 Treves A, Rolls ET: Computational analysis of the role of the hippocampus in memory. Hippocampus 1994;4:374-391.

22 Sahay A, Wilson DA, Hen R: Pattern separation: a common function for new neurons in hippocampus and olfactory bulb. Neuron 2011;70:582-588.

23 Saxe MD, Battaglia F, Wang JW, Malleret G, David DJ, Monckton JE, et al: Ablation of hippocampal neurogenesis impairs contextual fear conditioning and synaptic plasticity in the dentate gyrus. Proc Natl Acad Sci U S A 2006;103:17501-17506.

24 Snyder JS, Kee N, Wojtowicz JM. Effects of adult neurogenesis on synaptic plasticity in the rat dentate gyrus. J Neurophysiol 2001;85: 2423-2431.

25 Ben-Ari Y, Khazipov R, Leinekugel X, Caillard O, Gaiarsa JL: GABAA, NMDA and AMPA receptors: a developmentally regulated 'menage à trois'. Trends Neurosci 1997;20:523-529.

26 Contestabile A, Greco B, Ghezzi D, Tucci V, Benfenati F, Gasparini L: Lithium rescues synaptic plasticity and memory in Down syndrome mice. J Clin Invest 2013;123:348-361.
Long-Term Potentiation after Brain Irradiation 
-27 Li Q, Li H, Roughton K, Wang X, Kroemer G, Blomgren K, et al: Lithium reduces apoptosis and autophagy after neonatal hypoxia-ischemia. Cell Death Dis 2010;1:e56.

28 Li H, Li Q, Du X, Sun Y, Wang X, Kroemer G, et al: Lithium-mediated long-term neuroprotection in neonatal rat hypoxia-ischemia is associated with antiinflammatory effects and enhanced proliferation and survival of neural stem/progenitor cells. J Cereb Blood Flow Metab 2011;31:2106-2115.

29 Malaterre J, McPherson CS, Denoyer D, Lai E, Hagekyriakou J, Lightowler S, et al: Enhanced lithium-induced brain recovery following cranial irradiation is not impeded by inflammation. Stem Cells Transl Med 2012;1:469479.

-30 Yazlovitskaya EM, Edwards E, Thotala D, Fu A, Osusky KL, Whetsell WO Jr, et al: Lithium treatment prevents neurocognitive deficit resulting from cranial irradiation. Cancer Res 2006;66:11179-11186.

31 Huo K, Sun Y, Li H, Du X, Wang X, Karlsson $\mathrm{N}$, et al: Lithium reduced neural progenitor apoptosis in the hippocampus and ameliorated functional deficits after irradiation to the immature mouse brain. Mol Cell Neurosci 2012;51:32-42.

- 32 Roughton K, Andreasson U, Blomgren K, Kalm M: Lipopolysaccharide-induced inflammation aggravates irradiation-induced injury to the young mouse brain. Dev Neurosci 2013;35:406-415.

33 Hanse E, Gustafsson B: Postsynaptic, but not presynaptic, activity controls the early time course of long-term potentiation in the dentate gyrus. J Neurosci 1992;12:3226-3240.

34 McNaughton BL, Douglas RM, Goddard GV: Synaptic enhancement in fascia dentata: cooperativity among coactive afferents. Brain Res 1978;157:277-293.
35 Debanne D, Guerineau NC, Gahwiler BH, Thompson SM: Paired-pulse facilitation and depression at unitary synapses in rat hippocampus: quantal fluctuation affects subsequent release. J Physiol 1996;491:163-176.

36 Dobrunz LE, Stevens CF: Heterogeneity of release probability, facilitation, and depletion at central synapses. Neuron 1997;18:995-1008.

37 Bostrom M, Kalm M, Karlsson N, Hellstrom Erkenstam N, Blomgren K: Irradiation to the young mouse brain caused long-term, progressive depletion of neurogenesis but did not disrupt the neurovascular niche. J Cereb Blood Flow Metab 2013;33:935-943.

38 Fukuda H, Fukuda A, Zhu C, Korhonen L, Swanpalmer J, Hertzman S, et al: Irradiationinduced progenitor cell death in the developing brain is resistant to erythropoietin treatment and caspase inhibition. Cell Death Differ 2004;11:1166-1178.

39 Song J, Sun J, Moss J, Wen Z, Sun GJ, Hsu D, et al: Parvalbumin interneurons mediate neuronal circuitry-neurogenesis coupling in the adult hippocampus. Nat Neurosci 2013;16 1728-1730.

40 Acsady L, Kamondi A, Sik A, Freund T, Buzsaki G: GABAergic cells are the major postsynaptic targets of mossy fibers in the rat hippocampus. J Neurosci 1998;18:3386-3403.

41 Abrahamsson T, Gustafsson B, Hanse E: Synaptic fatigue at the naive perforant path-dentate granule cell synapse in the rat. J Physiol 2005;569:737-750.

42 Chancey JH, Adlaf EW, Sapp MC, Pugh PC, Wadiche JI, Overstreet-Wadiche LS: GABA depolarization is required for experience-dependent synapse unsilencing in adult-born neurons. J Neurosci 2013;33:6614-6622.
43 Ikrar T, Guo N, He K, Besnard A, Levinson S, Hill A, et al: Adult neurogenesis modifies excitability of the dentate gyrus. Front Neural Circuits 2013;7:204

-44 Ge S, Yang CH, Hsu KS, Ming GL, Song H: A critical period for enhanced synaptic plasticity in newly generated neurons of the adult brain. Neuron 2007;54:559-566.

45 Wang S, Scott BW, Wojtowicz JM: Heterogenous properties of dentate granule neurons in the adult rat. J Neurobiol 2000;42:248257.

46 Nabavi S, Kessels HW, Alfonso S, Aow J, Fox R, Malinow R: Metabotropic NMDA receptor function is required for NMDA receptor-dependent long-term depression. Proc Natl Acad Sci U S A 2013;110:4027-4032.

47 Babiec WE, Guglietta R, Jami SA, Morishita W, Malenka RC, O’Dell TJ: Ionotropic NMDA receptor signaling is required for the induction of long-term depression in the mouse hippocampal CA1 region. J Neurosci 2014;34:5285-5290.

- 48 Sahay A, Scobie KN, Hill AS, O'Carroll CM Kheirbek MA, Burghardt NS, et al: Increasing adult hippocampal neurogenesis is sufficient to improve pattern separation. Nature 2011; 472:466-470.

49 Vivar C, van Praag H: Functional circuits of new neurons in the dentate gyrus. Front Neural Circuits 2013;7:15.

50 Denny CA, Burghardt NS, Schachter DM Hen R, Drew MR: 4- to 6-week-old adultborn hippocampal neurons influence novelty-evoked exploration and contextual fear conditioning. Hippocampus 2012;22:11881201.

51 Kheirbek MA, Klemenhagen KC, Sahay A, Hen R: Neurogenesis and generalization: a new approach to stratify and treat anxiety disorders. Nat Neurosci 2012;15:1613-1620. 